\title{
A Practical Study on the Flipped Class upon MOOC in the Perspective of Big Data Age
}

\author{
Yang Chen ${ }^{1, \text { a }}$ \\ ${ }^{1}$ School of Foreign Languages, Wuhan University of Engineering Science, Wuhan, Hubei Province, \\ P. R. China \\ a313779235@qq.com
}

Keywords: MOOC, flipped class, group interaction, feasibility.

\begin{abstract}
With the boom of knowledge economy, the global education is being confronted with a drastic revolution. MOOC, as a kind of special teaching resource on line, has been rapidly accepted by learners around the world, due to its abundance in database, equivalence in knowledge sharing and low-cost in maintainability and operation.[1, 2] This paper thus, taking the specialized course in English department of Wuhan University of Engineering Science, a private owned independent college as the case, managed to design a flipped teaching mode based upon MOOC, and conducted an experimental teaching for a whole semester, together with three tests (pre-test to determine the feasibility of data comparison, mid-test to inspect the process, and final test to illustrate the feasibility of MOOC teaching in independent colleges) to testify the feasibility and significance of MOOC operation for local and especially private owned colleges, which is probably an effective and efficient solution to survive the competition for educational resources.
\end{abstract}

\section{Introduction}

With the boom of knowledge economy, the global education is being confronted with a drastic revolution. Since the establishment of on line courses by the professors from Stanford University based upon part of MOOC function, Mooc, the copyable teaching framework, organized by traditional classroom has become popular among students of different ages due to its free-to-communicate characteristics in American and European countries. New York Times even named 2012 the first year of MOOC in U.S.A, which symbols the initiation of MOOC hurricane around the world. MOOC, as a kind of special teaching resource on line, has been rapidly accepted by learners around the world, due to its abundance in database, equivalence in knowledge sharing, and low-cost in maintainability and operation. Therefore, universities and colleges around the world, especially those of first grade represented by Cambridge, Oxford, Tsinghua, and Beijing University, has become desperate in occupying the educational market organized by MOOC, in order to take the initiative in the establishment and organization of this brand new area.[3-5] At meantime, many scholars both inside and outside China has conducted a large number of researches on it. Gyles, C. (2013), from the perspective of framework, thought that MOOC was a public on line platform where large amount of knowledge was stored.

\section{Experimental teaching}

Preparation. participants: 100 current senior students (English majored), divided equally into two groups according to the distribution of their pre-test results (of equal distribution in all levels), so as to ensure the comparability of quantitative results. Meanwhile, the English specialized course International Trade and Finance (ITN for short) taken as the empirical carrier, after preparation done (including teaching video recorded, exercises and test data provided, and FAQ database established), the experimental teaching based upon MOOC was conducted for a whole semester. After that, the results of mid-term and final test of both contrastive and experimental groups were taken to conduct a comparative analysis, via which the significance and feasibility of establishing specific flipped 
classroom based upon MOOC was testified through the calculation of difficulty coefficient (DC for short). The results of pre-testing are listed as below (collected via SPSS)

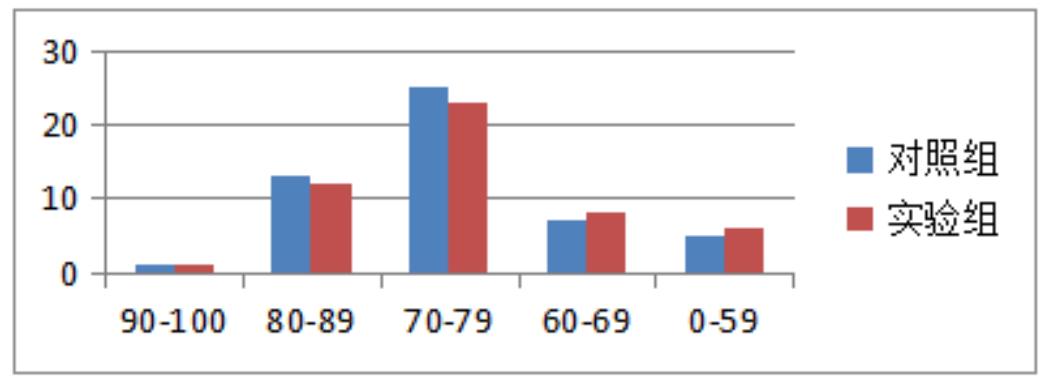

Fig. 1 results of pre-test (the difficulty degree is equivalent toTEM4)

The teaching procedures based upon MOOC. When participants were determined and preparation were done, flipped class was conducted in accordance with the teaching scheme by knowledge points towards the experimental group. On the other hand, the contrastive group were still taught via traditional procedures where "teacher has the say". The teaching scheme was kept in breast with the experimental group. The teaching procedures for the experimental group is shown as in fig. 2

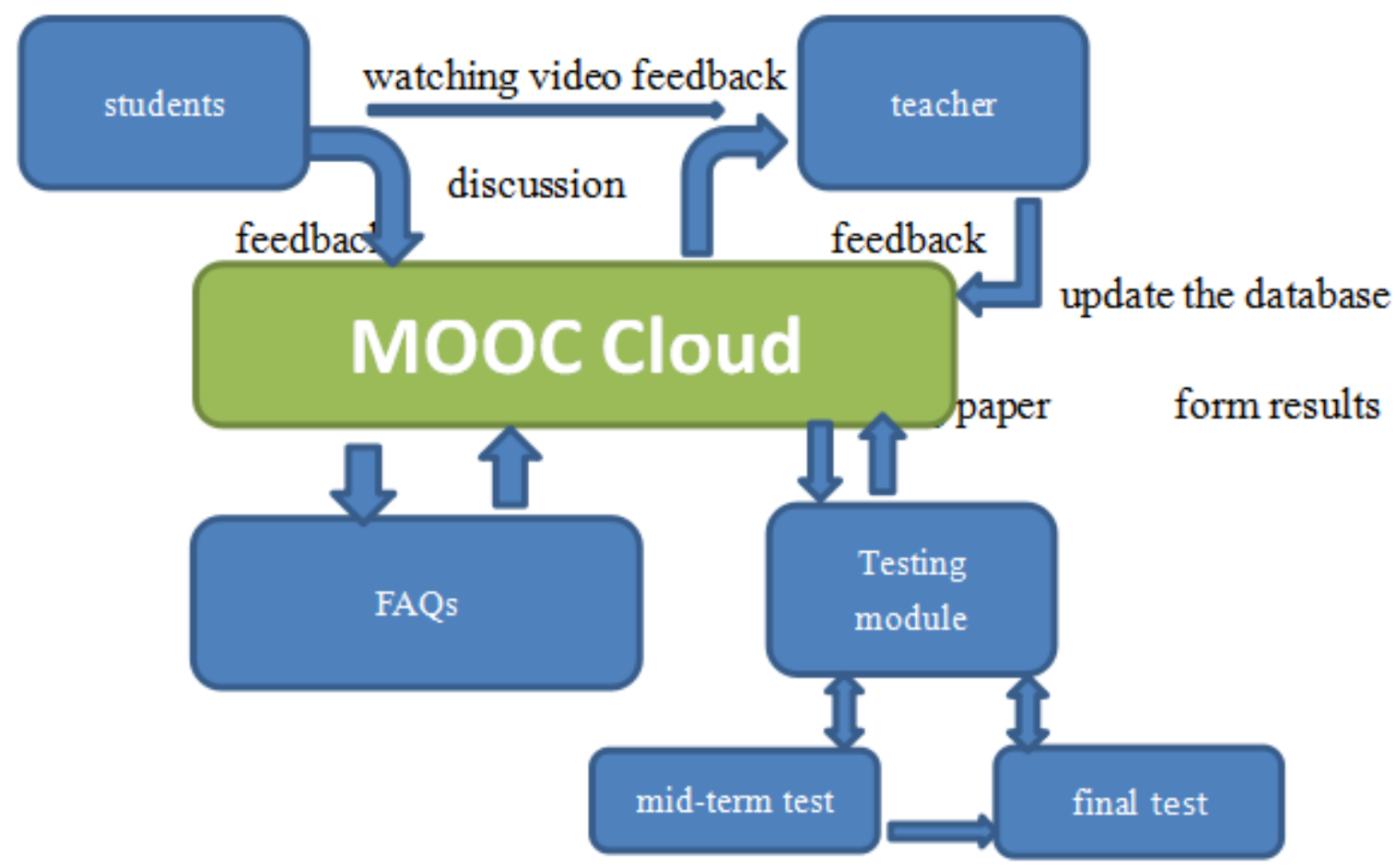

\section{Data collection and analysis.}

Mid-term test. According to the results of mid-test, the linguistic difficulty was of TEM4-6, the number of knowledge points (NKP) was determined by test syllabus and teaching scheme of Integrated English. The DC was set in accordance with the experimental group, with 0.4 the threshold. The DC listed in table 1 was calculated according to the difficulty function for samples.

Table 1. Mid-test results

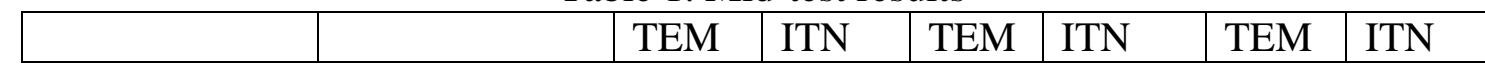

Seen from the above data, after 2 months of experimental teaching, the DC of TEM 4 for experimental group decreased, whereas that for contrastive group still stayed around 0.3, with little progress. Meanwhile, according to the requirements of ITN, the former teaching duration covers 23 knowledge points. After testing, the DC for experimental group was 0.251 , which indicates a general ideal mastering of professional knowledge for experimental group. In contrast, the DC for contrastive group is 0.323 , which means a much poorer performance, nevertheless with the same faculty and 
hardware teaching support. However, due to the limitation of duration probably, the differentiation is not obvious.

Final test. According to the mid-test results collected and analyzed, the author improved the difficulty of language for teaching to TEM 8. At the same time, the author arranged the teaching contents of ITN for the latter part. In the same way, the DC was in accordance with the experimental group, maintained below 0.4 , the threshold. The DC listed in table 2 was calculated according to the difficulty function for samples.

Table 2. Final-test results

\begin{tabular}{|c|c|c|c|c|c|c|c|}
\hline \multirow[t]{2}{*}{ Group } & \multirow{2}{*}{$\begin{array}{l}\text { Testing } \\
\text { phase } \\
\text { Time }\end{array}$} & \multicolumn{2}{|l|}{ NKP } & \multicolumn{2}{|c|}{$\begin{array}{l}\text { Average level } \\
(50+50)\end{array}$} & \multicolumn{2}{|l|}{ DC } \\
\hline & & TEM & ITN & TEM & ITN & TEM & ITN \\
\hline $\begin{array}{l}\text { Contrastive } \\
\text { group }\end{array}$ & $\begin{array}{l}\text { Final-test } \\
\text { (90min) }\end{array}$ & $11 / 24$ & $21 / 42$ & 28.75 & 28.76 & 0.425 & 0.425 \\
\hline $\begin{array}{l}\text { Experimental } \\
\text { group }\end{array}$ & $\begin{array}{l}\text { Final-test } \\
\text { (90min) }\end{array}$ & $11 / 24$ & $21 / 42$ & 40.12 & 39.10 & 0.198 & 0.218 \\
\hline
\end{tabular}

Seen from the above data, after the experimental teaching for the latter two months, the DC of TEM was still on a decrease; nevertheless the difficulty was improved to TEM8, which indicates a good comprehension of TEM theoretical knowledge, and a good performance of ITF upon MOOC, which is reflected in the decrease of DC of ITN (0.218). However, due to the traditional procedures, after the improvement of linguistic difficulty to TEM8, the DC of TEM8 towards the contrastive group was increased to 0.425 , exceeding the threshold(0.4). At the meantime, due to the improvement of linguistic difficulty, the learning effect (contrastive group) was poor, reflected in the increase of DC of ITN to 0.425, exceeding the threshold(0.4).

\section{Conclusion}

Through mid and final test, it is obvious that the teaching and learning effect of flipped class upon MOOC is generally better than that of traditional classroom, since this advanced mechanism manages to make full use of concentration of participants, which contributes much to the inner construction of knowledge framework. Besides, the in-class discussion further enhances the comprehension of the theoretical knowledge via students' self-solution of problems, which convinces participants that they are capable of coping with challenges all by themselves via interactions among students and between teacher and students. This, to the largest extent, improves the teaching efficiency and effect.

\section{References}

[1] Hossain, M.S., et al., A massive open online course (MOOC) can be used to teach physiotherapy students about spinal cord injuries: a randomised trial. J Physiother, 2015. 61(1): p. 21-7.

[2] Gyles, C., Is there a MOOC in your future? Can Vet J, 2013. 54(8): p. 721-4.

[3] Heller, R.F., Learning by MOOC or by crook. Med J Aust, 2014. 200(4): p. 192-3.

[4] Ishiwata, S., et al., Spontaneous tension oscillation (SPOC) of muscle fibers and myofibrils minimum requirements for SPOC. Adv Exp Med Biol, 1993. 332: p. 545-54; discussion 555-6.

[5] King, C., A. Robinson, and J. Vickers, Online education: Targeted MOOC captivates students. Nature, 2014. 505(7481): p. 26.

[6] Qu, H. and Q. Chen, Visual Analytics for MOOC Data. IEEE Comput Graph Appl, 2015. 35(6): p. 69-75.

[7] Reich, J., Education research. Rebooting MOOC research. Science, 2015. 347(6217): p. 34-5. 
[8] 2014 IEEE International Conference on MOOC, Innovation and Technology in Education. 389 pages.

[9] Learning technology for education in cloud : MOOC and big data. Third International Workshop, LTEC 2014, Santiago, Chile, September 2-5, 2014. Proceedings. 1st edition. ed. Communications in computer and information science. pages $\mathrm{cm}$.

[10] Hubbard, R.L., Getting the most out of MOOC : massive open online courses. First edition. ed. Digital and information literacy. 48 pages. 